\title{
A EDUCAÇÃO AMBIENTAL NO CONTEXTO DA ESCASSEZ HÍDRICA: O RACIONAMENTO NO DISTRITO FEDERAL ENTRE 2017 E 2018
}

\author{
Irineu Tamaio ${ }^{1}$
}

Genilson Carlos das Chagas $^{2}$

Resumo: De janeiro de 2017 a junho de 2018, o Distrito Federal (DF) enfrentou uma escassez hídrica que provocou o racionamento no abastecimento de água e atingiu principalmente as populações em situação de vulnerabilidade socioambiental. A partir desse evento climático extremo, este estudo investigou o papel da Educação Ambiental enquanto ação de política pública em períodos de escassez dos recursos hídricos. Trata-se de uma pesquisa documental, orientada pelo referencial teórico-metodológico da Educação Ambiental Crítica. A análise evidenciou que, como ação emergencial de política pública para o enfrentamento desse evento extremo no DF, a Educação Ambiental esteve associada à macrotendência político-pedagógica conservadora e pragmática.

Palavras-chave: Educação Ambiental; Recursos Hídricos; Escassez Hídrica; Racionamento de Água.

\begin{abstract}
From January 2017 to June 2018, the Brazilian Federal District faced a water scarcity that caused a rationing of water supply, having mainly affected socio-environmentally vulnerable populations. Considering this extreme climatic event, this study investigated the role of Environmental Education as a public policy action in periods of scarcity of water resources. It is a documentary research, guided by the theoretical and methodological framework of Critical Environmental Education. The analysis showed that Environmental Education, developed as an emergency public policy action to face this extreme event in the Brazilian Federal District, was associated with pragmatic and conservationist political-pedagogical macro-trend.
\end{abstract}

Keywords: Environmental Education; Water Resources; Water Scarcity; Water Rationing.

\footnotetext{
1 Universidade de Brasília - UnB (ProfÁgua). E-mail: irineu@unb.br, Link para o Lattes: http://lattes.cnpq.br/4484596458839997

2 Instituto Federal do Amazonas - Campus São Gabriel da Cachoeira. E-mail: genilson.chagas@ifam.edu.br, Link para o Lattes: http://lattes.cnpq.br/1020018044761406
}

Revista brasileira educação ambiental 


\section{Introdução}

Quando o assunto é disponibilidade hídrica, o Brasil é considerado uma potência mundial, pois o território brasileiro concentra aproximadamente $12 \%$ de todas as reservas de água doce do mundo (OCDE, 2015). Entretanto, apesar de toda essa riqueza hídrica, a água está distribuída de forma desigual no território nacional. De fato, há uma desproporção tanto em relação à distribuição hídrica, em termos da distribuição espacial desse recurso, quanto em relação ao seu acesso.

Exemplo disso foi a escassez hídrica enfrentada pelo Distrito Federal (DF) entre janeiro de 2017 e junho de 2018. Situação incomum até então, esse evento extremo provocou um racionamento da disponibilidade de água, tendo atingindo desde o uso residencial, comercial e industrial até o agrícola. Algumas explicações foram, então, propostas como possíveis causas para essa crise:

O Distrito Federal, ao longo dos anos, vem sofrendo os efeitos das mudanças climáticas e degradação do meio ambiente, consequências do desmatamento predatório da vegetação típica do Cerrado, de captações clandestinas de água, das ocupações irregulares que ocasionaram a impermeabilização do solo e do assoreamento de mananciais e nascentes. Durante os últimos anos tem-se observado que os índices de precipitação no Distrito Federal mantiveram-se abaixo da média (estiagem), contribuindo para diminuição dos níveis dos reservatórios, tanto do Descoberto quanto o de Santa Maria (GDF, 2017a, p. 3).

Percebe-se que são vários os fatores listados como possíveis causas da escassez hídrica no DF. Confrontadas com esse problema, as políticas públicas de Educação Ambiental (EA) podem contribuir para minimizar tais causas estruturais e fazer com que as pessoas reflitam sobre a situação. Tema central desta pesquisa sobre os recursos hídricos, a EA pode ainda estimular de forma contínua, e não apenas em tempos de crise - o consumo consciente e autônomo por parte da população, dos setores econômicos e da sociedade como um todo.

Entre as políticas públicas de EA para a gestão dos recursos hídricos, está a de tendência crítica - essa será a tendência proposta neste estudo. Tal tendência propõe uma outra abordagem para a relação entre a sociedade e os seus mais variados atores no que diz respeito ao uso dos recursos naturais e, mais especificamente, da água. Sendo assim, ela pode contribuir para estimular a participação da sociedade no enfrentamento de eventos climáticos extremos, como a referida crise hídrica enfrentada pelo DF.

Nos últimos anos, foram observados problemas de abastecimento em virtude de escassez de água também em outras regiões do país, como no estado de São Paulo e no semiárido. Assim, diante desse cenário, torna-se 
importante compreender o papel da $E A$ em relação à questão hídrica e às suas crises. É oportuno frisar que, especialmente em momentos de crise, os gestores públicos exigem da população uma redução do consumo de água. Por isso, entendemos que a EA é essencial enquanto uma política pública de Estado, de uma forma que possibilite à sociedade atuar como protagonista em todo o processo da gestão, tanto nos períodos de crise quanto em tempos ditos de normalidade.

A compreensão da importância da água passa pelo reconhecimento de que esse recurso natural é um bem público, insubstituível e estratégico, de dimensões e usos múltiplos, dotado de valor econômico, vulnerável à ação antrópica, que desempenha uma função social e que está na essência da vida cotidiana. Trata-se da base da nossa saúde. Portanto, não pode e não deve ser visto meramente como uma "mercadoria", que se usa sem limites e que sempre estará disponível, sendo "produzida" infinitamente (ROSSI, 2018). Partindo dessa compreensão social da água, esta pesquisa analisou o papel da EA em um momento de escassez hídrica, a partir da referida experiência de racionamento no DF entre os anos de 2017 e 2018.

\title{
As políticas públicas de EA na conjuntura da escassez
}

Para Sorrentino et al. (2005), uma EA, construída enquanto política pública, necessita do envolvimento dos vários atores sociais, de modo a que eles possam desempenhar uma gestão territorial na qual se promova uma educação crítica e emancipatória. Quanto a isso, os autores (2005) destacam que:

\begin{abstract}
a construção de uma Educação Ambiental como política pública implica processos de intervenção direta, regulamentação e contratualismo que fortalecem a articulação de diferentes atores sociais (nos âmbitos formal e não formal da educação) e sua capacidade de desempenhar gestão territorial sustentável e educadora, formação de educadores ambientais, educomunicação socioambiental e outras estratégias que promovam a EA crítica e emancipatória. E ainda, implicarão uma crescente capacidade do Estado de responder, mesmo que com mínima intervenção direta, às demandas que surgem do conjunto articulado de instituições atuantes dessa EA (SORRENTINO et al., 2005, p. 285).
\end{abstract}

Ao educar para a cidadania, a EA pode construir uma possibilidade da ação política, com o objetivo de contribuir para formar uma coletividade que é responsável pelo mundo que habita. Tal educação está fundada em: 
[...] um processo educativo que conduz a um saber ambiental materializado nos valores éticos e nas regras políticas de convívio social e de mercado, que implica a questão distributiva entre benefícios e prejuízos da apropriação e do uso da natureza (SORRENTINO et al., 2005, p. 288).

Assim, enquanto política pública, a EA tem um papel importante na questão hídrica e durante momentos de escassez desse recurso, devido à sua capacidade de empoderamento da sociedade na participação ativa e crítica em relação às questões ambientais. De acordo com Diniz e Maranhão (2011), para ser consistente,

[...] uma política de Educação Ambiental deve considerar a necessidade histórica da transição para uma nova sociedade, pautada pelo bem comum. Deve promover, portanto, valores socioambientais, com base no empoderamento e soberania popular, na participação e na mudança de atitudes e comportamentos, no diálogo entre só diversos atores e no desenvolvimento de ações individuais e coletivas (DINIZ; MARANHÃO, 2011, p. 75).

Conforme afirmam os autores (2011), a política pública de EA deve estar em sintonia com as demandas socioambientais. Nesse contexto, a sociedade é chamada a participar de forma autônoma, consciente e sabendo do seu papel no exercício da cidadania. Portanto, o grande desafio é garantir a participação social na gestão ambiental e dos recursos hídricos. Dessa forma, deve-se esclarecer que:

[...] os principais papéis da Educação Ambiental se relacionam à informação e a capacidade de interpretação e análise. Os PEAs [Programas de Educação Ambiental] devem favorecer o acesso da sociedade a informações claras sobre a realidade socioambiental, destacadamente sobre os usos e usuários da água, os conflitos e impactos associados a esses usos, a qualidade da água, os papeis dos diferentes atores sociais e os instrumentos da PNRH [Política Nacional de Recursos Hídricos]. Mais que acessar informações claras, a população precisa ampliar progressivamente sua capacidade de interpretar informações socioambientais. Esse é um desafio pedagógico e político da Educação Ambiental. É preciso desenvolver processos, com a base da sociedade, que ao mesmo tempo propiciem diagnósticos e planejamentos socioambientais, ampliem a capacidade de interpretação dos coletivos e indivíduos e a qualidade da participação e da representatividade nos diferentes colegiados ambientais (PAULA JÚNIOR; MODAELLI, 2013, p. 13). 
Diante de todas essas questões, um dos grandes desafios da EA enquanto política de gestão dos recursos hídricos é possibilitar ações e movimentos que estimulem a sociedade a atuar como protagonista e indutora de políticas públicas. Com informações claras e precisas, os cidadãos podem atuar como agentes de representatividade e participação efetiva. Essa educação pode, assim, contribuir para o engajamento político da sociedade na questão da água e ajudar a lidar de forma preventiva com a escassez desse recurso.

Outro grande desafio que se coloca para a EA enquanto política pública permanente em relação à questão hídrica é a sua implementação em momentos de crise. Trata-se de uma enorme lacuna que se deve enfrentar na atualidade, tendo em vista as últimas duas grandes crises hídricas que ocorreram no Brasil, situações extremas até então inimagináveis - uma no estado de São Paulo e a outra no DF. Além disso, é preciso considerar o caótico cenário advindo da emergência climática, que se agravará especialmente para os grupos em situação de vulnerabilidade socioambiental. Com mais frequência, tais grupos enfrentarão graves crises de disponibilidade de água. Isso exigirá dessa população desassistida mais intervenção política na esfera pública, de modo a lutar pela garantia do direito humano de acesso à água em meio ao colapso climático iminente (GAUDIANO; CARTEA, 2020; LAYRARGUES, 2020b; SATO et al., 2020; PAULA JÚNIOR; ZARDO, 2019).

\section{Correntes e tendências da EA}

A EA teve uma trajetória histórica que resultou em várias correntes e tendências e em diferentes conceituações e classificações, de acordo com suas características e abordagens. Ao desenvolver um estudo de reflexão sobre o tema em questão, Layrargues e Lima (2014, p. 27) afirmam que, com o passar do tempo, "os educadores ambientais perceberam que, da mesma maneira que existem diferentes concepções de natureza, meio ambiente, sociedade e educação, também existem diferentes concepções de Educação Ambiental'. Por outras palavras, se para o campo pedagógico e para as correntes ambientalistas foram sendo estabelecidas várias vertentes, para a EA não foi diferente. Assim, segundo os autores (2014), tal educação deixou de ser vista de uma forma única, passando a ser compreendida com base em uma perspectiva plural.

Hoje, são identificadas diferentes correntes e tendências, cada uma com peculiaridades que as diferenciam umas das outras. Layrargues e Lima (2014) listam três macrotendências político-pedagógicas para a EA no Brasil, a saber: a conservacionista, a pragmática e a crítica. Essas três vertentes político-pedagógicas discutidas por esses autores (2014) foram selecionadas como referencial teórico e analítico deste trabalho. Cada uma tem características específicas, mas, conforme se verá adiante, duas delas partilham algumas similaridades. 
A macrotendência conservacionista, à qual a EA foi inicialmente atrelada, baseia-se em uma perspectiva um tanto romântica dos cuidados com a natureza. O seu fundamento é a ciência ecológica, que se configura como uma prática pautada pela sensibilização para o culto à natureza, para a preservação e para a conscientização ecológica (LAYRARGUES; LIMA, 2014). Layrargues e Lima (2014) observam que essa macrotendência se expressa por meio de outras correntes, tais como:

[...] correntes conservacionistas, comportamentalista, da Alfabetização Ecológica, do autoconhecimento e de atividades de senso-percepção ao ar livre, vincula-se aos princípios da ecologia, na valorização da dimensão afetiva em relação à natureza e na mudança do comportamento individual em relação ao ambiente baseada no pleito por uma mudança cultural que relativize o antropocentrismo. É uma tendência histórica, forte e bem consolidada entre seus expoentes, atualizada sob as expressões que vinculam Educação Ambiental à 'pauta verde', como biodiversidade, unidades de conservação, determinados biomas, ecoturismo e experiências agroecológicas (LAYRARGUES; LIMA, 2014, p. 30).

Trata-se de representações bastante ligadas apenas à questão ambiental, que não fazem nenhum tipo de crítica ao modelo econômico, exploratório, liberal e capitalista que está na base dos problemas ambientais. Ao ser transposta para o campo da educação, essa abordagem está ligada a um projeto conservador. De acordo com Guimarães (2013, p. 16), tal projeto está amparado em uma visão liberal de mundo, que acredita que a transformação da sociedade é consequência da "transformação de cada indivíduo, visto como seres em absoluta autonomia; a transformação depende da vontade individual'. Dessa forma, a educação seria o suficiente para resolver os problemas da sociedade, precisando apenas mostrar a cada indivíduo como chegar àquilo que se entende como correto. O indivíduo, por si só, deverá desenvolver um comportamento adequado, a partir de uma educação totalmente desvinculada da prática, ou seja, de uma educação apenas teórica, transmissora, despolitizada ou "bancária", como descreveu Paulo Freire (GUIMARÃES, 2013).

Assim, essa corrente associa à esfera individual a responsabilidade pela mudança de comportamento e de resolução dos problemas ambientais, sob a alegação de que isso seria o suficiente para resolver tais questões. Essa defesa, ao que parece, não se sustenta por si só. Nesse sentido, para Bomfim e Dias (2011), o que falta à EA conservadora é: 
[...] uma reflexão sobre a sua própria prática. Na maioria das vezes, esta se limita a iniciativas estereotipadas, pontuais e pré-fabricadas, observadas em projetos em escolas, comunidades, unidades de conservação, meios de comunicação, empresas, como por exemplo, a coleta seletiva de lixo, o plantio de mudas de árvores e a realização de semanas ambientais. Estas práticas em 'Educação Ambiental' encontram-se, quase sempre, descontextualizadas da realidade socioambiental em questão. (BOMFIM; DIAS, 2011, p. 2).

Segundo Bomfim e Dias (2011), os atores envolvidos no processo nem sempre estão habilitados a entender criticamente as dimensões econômicas, históricas, biológicas e sociais dos problemas socioambientais. Isso faz da EA conservadora um conjunto de práticas pouco críticas, que não questionam as verdadeiras raízes do problema, ficando, assim, na superfície da discussão.

Já a macrotendência pragmática, de acordo com Layrargues e Lima (2014), está baseada na resolução dos problemas com o propósito de se ajustar aos mecanismos do mercado e da política neoliberal no campo econômico. Ela foi cooptada por tais ideologias e é conduzida sob um viés despolitizado em relação às questões sociais e culturais e às desigualdades socioeconômicas - ou seja, tal abordagem não apresenta denúncias ou proposições contundentes para reverter as distorções $e$ as injustiças recorrentes ligadas às questões ambientais; ela apenas se "vestiu" de uma nova "roupagem" de uma tendência já existente.

Layrargues e Lima (2014, p. 31) afirmam que "a macrotendência pragmática tem suas raízes no estilo de produção e consumo advindos do pósguerra". Talvez por isso ela tenha se adaptado a esse novo momento, pois foi nesse período que começou a se intensificar o processo de expansão das multinacionais pelo mundo, principalmente para os países subdesenvolvidos. Para o sucesso desse projeto, era necessário incentivar cada vez mais o consumo e promover a "obsolescência planejada" dos produtos" (LAYRARGUES; LIMA, 2014, p. 31), o que representa um passivo ambiental enorme. O caminho encontrado por essa tendência foi o de "educar" esse novo cidadão consumidor no sentido de fazê-lo adotar o que seriam pretensamente boas práticas ambientais. A proposta restringe-se, portanto, a mudanças comportamentais (LAYRARGUES; LIMA, 2014). Os autores (2014) esclarecem que essa tendência:

[...] abrange, sobretudo, as correntes da Educação para o Desenvolvimento Sustentável e para o Consumo Sustentável, é expressão do ambientalismo de resultados, do pragmatismo contemporâneo e do ecologismo de mercado que decorrem da hegemonia neoliberal instituída mundialmente desde a década de 1980 e no contexto brasileiro desde o governo Collor de 
Mello nos anos 1990. Caracterizam esse cenário pragmático a dominância da lógica do mercado sobre as outras esferas sociais, a ideologia do consumo como principal utopia, a preocupação com a produção crescente de resíduos sólidos, a revolução tecnológica como última fronteira do progresso e a inspiração privatista que se evidencia em termos como economia e consumo verde, responsabilidade socioambiental, certificações, mecanismos de desenvolvimento limpo e ecoeficiência produtiva (LAYRARGUES; LIMA, 2014, p. 30-31).

Trata-se, assim, de uma abordagem também conservadora, que não faz críticas ao modelo exploratório vigente e que pode até simular uma preocupação com o meio ambiente, mas, na realidade, ajuda a manter tudo como está. Prevalece um crescimento econômico voraz, para poucas pessoas, em detrimento, de fato, de uma preocupação com as questões ambientais e sociais. Além disso, essa tendência considera o homem e o meio ambiente separadamente, de forma independente (LAYRAGUES; LIMA, 2014).

Layrargues e Lima (2014) apresentam ainda duas características do caráter pragmático dessa macrotendência que se complementam e que reduzem as possibilidades de um enfrentamento político da questão, mantendo o status quo. Os autores (2014) descrevem do seguinte modo essas duas características complementares:

[...] primeiro, a ausência de reflexão que permita a compreensão contextual e articulada das causas e consequências dos problemas ambientais. Essa ausência de reflexão deriva da crença na neutralidade da ciência e resulta em uma percepção superficial e despolitizada das relações sociais e de suas interações com o ambiente. Segundo, a busca desenfreada por ações factíveis que tragam resultados orientados a um futuro sustentável, embora dentro de um limite que não ultrapasse as fronteiras do realismo político, do economicamente viável, da conservação do status quo (LAYRARGUES; LIMA, 2014, p. 32).

Portanto, para Layrargues e Lima (2014), as duas macrotendências - a conservacionista e a pragmática - comportam-se como um ajustamento ao modelo político econômico vigente - neoliberal, capitalista, excludente e desigual. Fazem isso sem tecer críticas a esse modelo e/ou propor mudanças de paradigmas e estruturas, conforme ficou evidente no presente estudo.

A terceira macrotendência que Layrargues e Lima (2014) descrevem é a crítica. Ela destoa das duas anteriores, tanto no teor quanto na sua forma de leitura da conjuntura da questão ambiental. Segundo os autores (2014, p. 33), essa abordagem "aglutina as correntes da Educação Ambiental Popular, 
Emancipatória, Transformadora e no Processo de Gestão Ambiental'. Sendo assim, ela se configura como uma "revisão crítica dos fundamentos que proporcionam a dominação do ser humano e dos mecanismos de acumulação do Capital, buscando o enfrentamento político das desigualdades e da injustiça socioambiental' (LAYRARGUES; LIMA, 2014, p. 33)

Nessa mesma linha argumentativa, Guimarães (2004) compreende a EA crítica como uma outra abordagem, aquela que acredita contribuir para outra leitura de mundo, menos simplista e mais complexa, instrumentalizada para uma intervenção que contribua para o processo de transformação de uma realidade socioambiental complexa. Nessa perspectiva crítica, o conflito e as relações de poder são essenciais para a construção de sentidos e para a organização espacial em suas múltiplas determinações. Identifica-se, então, um conteúdo político, crítico e de denúncia em relação aos problemas, que passam a ser vistos não apenas sob o enfoque ambiental, mas socioambiental, incorporando o componente humano nos seus aspectos sociais e culturais, entre outros. Esse componente começa, assim, a fazer parte desse debate para o enfrentamento coletivo dos problemas ambientais.

De acordo com Guimarães (2004, p. 17), em uma proposta de EA crítica, trabalha-se com uma visão "sistêmica de meio ambiente, compreendido em sua totalidade complexa, por meio de um conjunto, no qual seus elementos/partes interdependentes interrelacionam entre si, entre as partes e $o$ todo, o todo nas partes". O autor (2014) destaca que o espaço natural veio historicamente sendo apropriado pelas sociedades humanas, transformando-se em um espaço socialmente produzido. Por isso, a corrente da EA crítica representa a possibilidade da formação de um cidadão mais atuante nas questões ambientais, contestador e inconformado com o que está posto. Não se trata mais de uma atitude domesticada e passiva em relação ao modelo capitalista, exploratório e insustentável. Pretende-se antes formar um sujeito ecopolítico, presente nas esferas públicas de disputas socioambientais (LAYRARGUES, 2020a).

A partir disso, percebe-se que, na EA crítica, ao contrário das correntes conservacionista e a pragmática, os componentes da transformação, da participação, da denúncia, da dialética e do social, entre outros, estão presentes e têm um objetivo bem definido: o de mudar o que está posto quando se fala em meio ambiente e da sua relação com o componente humano. O que se pretende, em suma, é uma perspectiva bem mais democrática e cidadã.

Por isso, para Bomfim e Dias (2011), a EA crítica está amparada em uma compreensão mais ampla do exercício da participação social e da cidadania, como prática essencial à vivência democrática e à emancipação socioambiental. Nesse sentido, "a democracia seria condição para a construção de uma sustentabilidade substantiva" (BOMFIM; DIAS, 2011, p. 3), algo que é indispensável a uma EA crítica. Trata-se, assim, de um tipo de EA 
que "busca incessantemente romper com as práticas sociais contrárias ao bem-estar público e à igualdade" (BOMFIM; DIAS, 2011, p. 3).

Bomfim e Dias (2011) comentam ainda que essa EA maximizou a sua abrangência na última década, principalmente no âmbito acadêmico, tendo demonstrado grande potencial para sair de uma condição contra hegemônica e ocupar um lugar central no campo atualmente dominado pela macrotendência pragmática. Assim, buscar "mudanças políticas que denunciam e combatem a insustentabilidade e [propor] a formação de sujeitos críticos, participativos e comprometidos com uma sustentabilidade socioambiental enquanto opção ético-política" (LAYRARGUES, 2020, p. 19) são tarefas inerentes a essa corrente da EA.

Considerando a gravidade da escassez hídrica, a urgência do desafio que tal escassez representa e as abordagens e proposições em relação ao objetivo e ao papel da EA crítica, indaga-se: em um evento extremo como o do racionamento no DF ocorrido entre 2017 e 2018, as ações emergenciais e políticas de sensibilização e de educação então propostas adotaram uma posição crítica? Como inserir uma EA crítica nas políticas públicas relacionadas à água em momentos de escassez? Com essas indagações em mente e com base nas reflexões sobre as macrotendências da EA desenvolvidas por Layrargues e Lima (2014), esta pesquisa adotou a concepção de EA crítica como instrumento de análise para as ações empreendidas pelas políticas públicas de educação e enfrentamento da escassez hídrica no DF.

No âmbito metodológico, este trabalho recorre à análise da temática da EA e dos recursos hídricos, a partir de documentos, atos e ações emergenciais propostas por órgãos do Governo do DF (GDF) no referido período de racionamento. Portanto, trata-se de uma pesquisa documental de cunho exploratório. Como critério de escolha para a análise dos documentos oficiais, foram considerados aqueles lançados e colocados em prática durante o período da crise de escassez hídrica de 2017-2018 e que tenham tido ações reconhecidas como de EA, com o intuito de enfrentar as consequências do evento extremo em questão. Foram selecionados trechos de documentos oficiais para análise de interpretação, a partir dos referenciais teóricos da EA crítica.

\section{Análise das ações de EA implementadas durante a escassez hídrica do DF}

Esta pesquisa analisou dois documentos oficiais do GDF que constituíram as principais ações implementadas no âmbito da crise de escassez hídrica no DF no período de 2017 a 2018, com propósito educativo. São eles:

1) o "Plano Integrado de Enfrentamento à Crise Hídrica" (2017a) e as suas duas dimensões - dimensão educação e dimensão comunicação; 
2) a cartilha "Mensageiros da Água - Orientações para práticas pedagógicas" (2017b), documento que, desenvolvido pelo Instituto Brasília Ambiental (Ibram), em parceria com a Secretaria de Estado de Educação do Distrito Federal (Seedf), a Companhia de Saneamento Ambiental do Distrito Federal (Caesb) e a Subsecretaria de Vigilância à Saúde (SVS/SES), apresenta dez dicas para um uso racional e econômico da água.

A dimensão educação do "Plano Integrado de Enfrentamento à Crise Hídrica" apresenta duas linhas de ação: uma voltada para as escolas públicas e a outra, para os agricultores. O plano explicita que tem como objetivo "enfatizar novas práticas para um consumo consciente, bem como a redução de desperdício de água" (GDF, 2017a, p. 60). Podemos enquadrar esse objetivo na corrente da EA conservadora, na medida em que, de acordo com Layrargues e Lima (2014), esse tipo de abordagem tende a estimular apenas uma mudança do comportamento individual em relação ao meio ambiente neste caso, em relação à água. O plano afirma ainda que a educação representa a "possibilidade de mudanças nos padrões de comportamento da população na sua relação com a água" (GDF, 2017a, p. 71). Isso vai ao encontro do que Layrargues e Lima (2014) afirmam, pois centra a ação apenas na redução do desperdício, sem debater as raízes dos problemas socioambientais que contribuíram para a escassez.

Em relação a esse aspecto, a própria Lei das Águas, em seu art. $2^{\circ}$, menciona a necessidade da utilização da água de forma "racional", de modo a assegurar a disponibilidade de tal recurso às futuras gerações. Isso se enquadraria também na questão do uso consciente enfatizado no plano do DF (BRASIL, 1997). Entretanto, esse uso racional está relacionado com o não desperdício, com utilizar de forma econômica para que não falte para os outros - ou seja, trata-se de uma forma um pouco simplista e despolitizada de enxergar a gestão dos recursos hídricos a partir dimensão da educação, sem uma proposta de ação mais profunda e estruturante (LAYRARGUES, 2018), considerando apenas a racionalização do uso desse recurso.

Simplificar a educação a uma proposta de "redução de desperdícios da água e gestão ambiental' (GDF, 2017a, p. 60) pode ser identificado como um limite dessa abordagem. Perde-se toda a riqueza de uma temática que é extremamente complexa. Como esclarece Layrargues (2018), para a questão da crise ambiental - e a água está inserida nessa crise, não é suficiente atuar apenas na gestão do meio ambiente e no enfrentamento da crise, se não se debater, dialogar e discutir as evidências da degradação ambiental e as suas causas estruturais. Portanto, em vez de ficarmos apenas nas causas superficiais e conjunturais que geram a crise hídrica e os seus demais desdobramentos, é necessário atuar e buscar alternativas do ponto de vista estrutural. Tal como Layrargues (2002) propõe, é preciso que a temática dos recursos hídricos seja um tema gerador na $E A$, e não atividade-fim, encerrada em si mesma. Por isso, ressignificar as práticas pedagógicas adotadas pela sociedade passam pela proposição de um aprendizado que fomente a reflexão 
sobre os impactos ambientais e que aponte caminhos para a superação das crises hídricas que vivenciamos.

Para Lima (2009), a educação pode desempenhar um papel de conservação e acomodação da ordem social, sendo reprodutora dos valores, das ideologias e dos interesses socialmente dominantes. É precisamente isso o que identificamos no plano quando nele é mencionada a necessidade de "sensibilizar e informar estudantes e professores com relação ao uso e conservação dos recursos hídricos" (GDF, 2017a, p. 60). Conforme mostram Lima (2009), Layrargues e Lima (2014) e Layrargues (2018), essa é uma visão que pode ser interpretada como conformadora e despolitizada da educação, a qual pode e deve ter um outro papel, firmando-se como emancipatória, comprometida com a renovação cultural, política e ética da sociedade e com o significativo desenvolvimento das potencialidades dos indivíduos que a compõem. Portanto, pode-se conceber que a dimensão crítica não esteve presente no conteúdo e nas ações emergenciais adotadas pelo GDF.

Em relação à linha de ação destinada aos agricultores do DF, o "Plano Integrado de Educação Hídrica" afirma que teve como "prioridade a capacitação e instrumentalização quanto ao uso dos aspersores convencionais que estão sendo substituídos por aspersores mais modernos" (GDF, 2017a, p. 60). Assim, o plano foi idealizado de forma a conscientizar para o uso da água de uma forma mais eficiente, por meio da capacitação e da instrumentalização quanto ao uso dos aspersores convencionais, menos eficientes, e que foram sendo substituídos por aspersores mais modernos, que utilizam menos água, mais eficientes. Isto é, observa-se aí uma ação de EA centrada apenas na redução do consumo, que pode, assim, ser enquadrada na tendência da EA pragmática, defendendo a ênfase no uso de tecnologias como solução para o alto consumo de água (LAYRARGUES; LIMA, 2014).

Acrescenta-se, quanto a isso, a crítica ao tipo de educação proposta ao público-alvo em questão - os agricultores. Essa educação pode ser mais uma vez caracterizada como de vertente pragmática, ao propor, por exemplo, apenas "colaborar com processos de sensibilização; capacitação; sistemas de irrigação mais poupadores e eficientes no uso da água [...]" (GDF, 2017a, p. 65). Trata-se de um ajustamento aos mecanismos de mercado no contexto neoliberal, com base na visão do ambientalismo de resultado e no uso de tecnologias modernas para um consumo eficiente da água (LAYRARGUES; LIMA, 2014).

Já na dimensão comunicação, o plano propôs a "publicação de campanhas/ações publicitárias sobre o uso racional da água" (GDF, 2017a, p. 71). As campanhas foram veiculadas nos mais variados meios de comunicação do DF. No contexto da comunicação e para alcançar os objetivos por meio dessas campanhas publicitárias, o plano cita a necessidade de: 
criar, produzir e veicular campanhas e ações publicitárias, com o objetivo de informar/orientar a população para o consumo consciente da água para evitar o desperdício, preparando a população para o momento do abastecimento comprometido. (GDF, 2017a, p. 72).

A campanha de comunicação em questão adotou diferentes slogans, como forma de conscientizar a população para a importância da economia no uso da água. As Figuras 1 e 2, reproduzidas a seguir, foram divulgadas em diferentes veículos de imprensa.

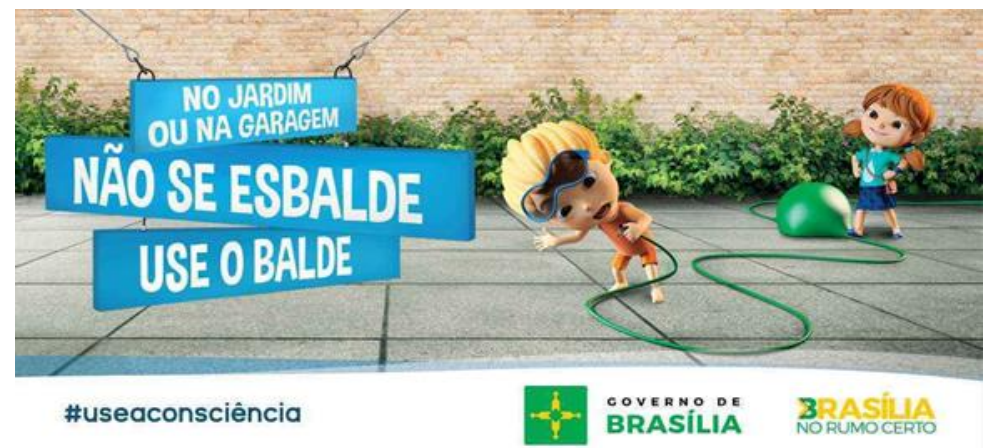

Figura 1: Economizando água com o balde.

Fonte: Secretaria de Estado de Comunicação (Secom) do DF (2017).

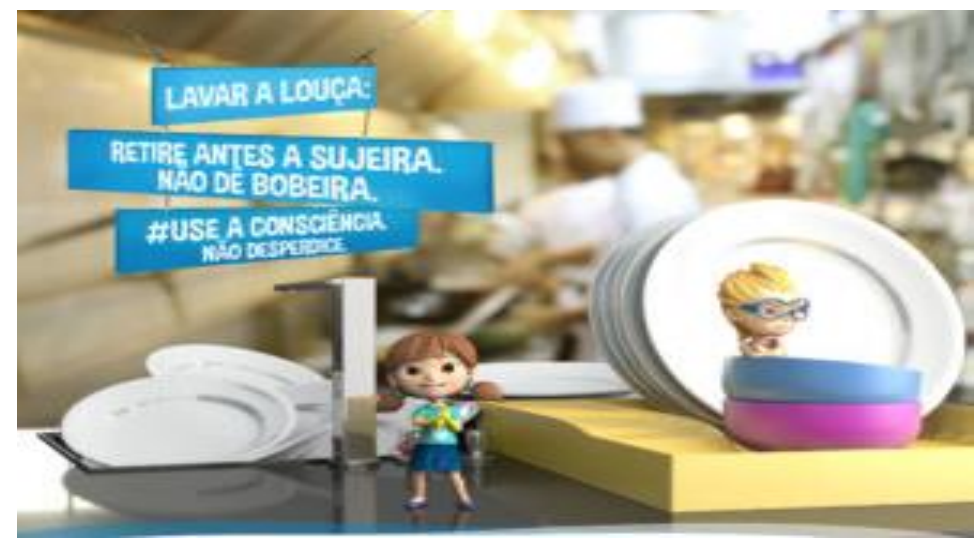

Figura 2: Economizando água ao lavar a louça. Fonte: Secom do DF (2017).

Nessas figuras, observa-se que as mensagens veiculadas são pautadas pela conscientização para 0 uso racional da água e para a importância de se evitar o desperdício. Novamente, a proposta está centrada na mudança comportamental e na redução do consumo, sem debater os conflitos e os interesses subjacentes ao acesso à água. Essa abordagem pode contribuir para o desenvolvimento de uma EA conservadora, despolitizada e acrítica (LAYRARGUES; LIMA, 2014). Pode estimular ainda uma educação que não vai à raiz do problema, centrando-se na autonomia dos sujeitos quanto ao 
consumo da água, vendo esse como o "caminho único" para a resolução dos problemas (GUIMARÃES; RODRIGUES, 2010).

Em relação ao aspecto pedagógico da EA conservadora, como podemos identificar nas mensagens nas Figuras 1 e 2 anteriores, tal tendência se apresenta de maneira individualista e comportamentalista, por defender que a origem dos problemas ambientais está mais inserida na esfera individual, moral e privada do que na esfera coletiva, pública e política. Com isso, voluntária ou involuntariamente, a EA conservadora se articula a uma significação liberal ou mesmo neoliberal da crise ambiental (LIMA, 2009).

Nesse sentido, pode-se afirmar que o objetivo principal das campanhas publicitárias do plano foi de "influenciar a opinião pública no sentido de se engajá-la na atitude de economizar água" (GDF, 2017a, p. 72), apenas como forma de transmitir o uso "correto" e econômico da água. Diante desse objetivo, podemos interpretar que "a discussão conduzida pela Educação Ambiental está consideravelmente deslocada do eixo da formação da cidadania enquanto atuação coletiva na esfera pública" (LAYRARGUES, 2002, p. 2). O papel do cidadão enquanto agente participativo, colaborativo e questionador fica, assim, para segundo plano na discussão de uma política pública de EA para a sociedade na qual esse mesmo cidadão está inserido. Dessa forma, ficam empobrecidas a legitimidade e a aceitação de tal política pública, passando o público-alvo a ser um mero receptor de informações.

O segundo documento a ser analisado é a cartilha "Mensageiros da Água", desenvolvida pelo Ibram em parceria com outros órgãos do GDF. O documento traz orientações para as práticas pedagógicas e inclui uma lista com dez dicas de como economizar e racionalizar o uso da água. As sugestões são:

- Mantenha a torneira fechada enquanto escova os dentes;

- Trate a água da piscina em vez de substituí-la a cada uso;

- Utilize a máquina de lavar com menos frequência acumulando roupas;

- Limpe a calçada com vassoura em vez de usar a mangueira;

- Feche a torneira mesmo que tenha sido aberta por outra pessoa;

- Procure conscientizar seus colegas ao ver alguns deles desperdiçando água;

- Mantenha a válvula da descarga regulada;

- Reduza um pouco do tempo que você gasta no banho;

- Pense em formas criativas de reaproveitar água ou reduzir o consumo;

- Diga não às ligações irregulares e aos vazamentos na rua: chame à Caesb (GDF, 2017b, p. 12). 


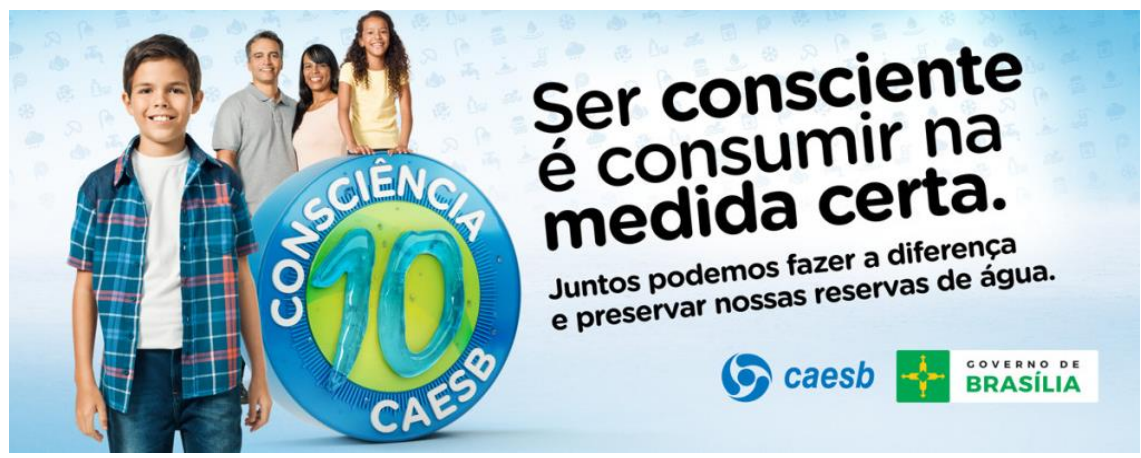

Figura 3: Consciência 10 da Caesb.

Fonte: Secom do DF (2017).

Como se pode perceber, a cartilha com as dez dicas (Figura 3) apresenta ações focadas no individualismo e no comportamentalismo. Trata-se de ações bem pontuais e superficiais, verdadeiros paliativos para fazer frente ao enfrentamento da escassez hídrica no DF. De fato, ações como "mantenha a torneira fechada enquanto escova os dentes" ou "feche a torneira mesmo que tenha sido aberta por outra pessoa", por si sós, não são suficientes para resolver e superar o problema. São necessárias antes propostas que estimulem o debate em relação aos conflitos e ao uso desigual da água pelos grupos sociais e econômicos, ao direito humano à água, ao modelo de agricultura que gera 0 alto consumo, à conservação de nascentes e das unidades de conservação, entre outros tópicos. Isso possibilitaria a reflexão das razões estruturais do problema e contribuiria para a formação de posturas e atitudes críticas importantes para fazer frente a momentos de escassez hídrica.

Portanto, tais dicas podem ser enquadradas como ações de abordagem da EA conservadora, comportamentalista e individual, colocando no indivíduo a responsabilidade por economizar água para fazer frente ao problema. A ideia que subjaz à publicação é a de que existe um caminho "correto" que passa por conselhos como "procure conscientizar seus colegas ao ver alguns deles desperdiçando água" ou "reduza um pouco do tempo que você gasta no banho", como se uma EA de cunho comportamentalista fosse o suficiente para solucionar os problemas decorrentes da escassez hídrica, conforme pontua Guimarães (2013). Essas orientações podem ser enquadradas também na abordagem que Layrargues e Lima (2014) chamaram de "Alfabetização Ecológica" - uma verdadeira cartilha, um norte ou um caminho a ser seguido.

Mensagens como "trate a água da piscina em vez de substituí-la a cada uso" ou "utilize a máquina de lavar com menos frequência acumulando roupas" colocam a ênfase no individualismo para o enfrentamento da crise e, novamente, podem ser caracterizadas como sendo da corrente EA conservacionista, haja vista a superficialidade que lhes é inerente, revelando certa ingenuidade no trato com a questão da escassez hídrica. Nessas dez dicas, observa-se também um conteúdo sem fundamentação crítica, centrado 
na mudança comportamental, sem uma proposta de repensar ou propor ações para mudanças no modelo capitalista de exploração e distribuição da água.

De acordo como Marcatto (2002), a EA tem que ser um processo dinâmico, integrativo, transformador, participativo, abrangente, globalizador, permanente, contextualizado e transversal. No entanto, percebe-se, a partir dos conteúdos das mensagens aqui problematizadas, que essa EA, abrangente e dinâmica, não foi contemplada na referida cartilha.

\section{Conclusões}

É importante entender que a água é um recurso natural finito e que o acesso a tal recurso é um direito humano, sem o qual não há vida. Portanto, a água não pode ser vista apenas como uma mercadoria, dotada de valor econômico, que pode ser usada sem uma preocupação com o risco do seu fim. A questão hídrica é complexa e requer um olhar crítico por parte das populações. Outra questão importante é a da relação que o ser humano estabelece com a natureza, relação essa que deve ser compreendida enquanto pertencente ao mundo no qual o indivíduo vive, pois ele não está apartado do meio natural. Por isso, toda forma de uso predatório dos recursos naturais neste caso específico, da água - em nome apenas do desenvolvimento econômico implica, aos poucos, uma autodestruição.

É necessário compreender também que a EA difundida pelo modelo econômico vigente, o qual é excludente, desigual e marcado por injustiça social, não tem nenhuma pretensão de mostrar a real necessidade de rever o modelo consumista, exploratório e insustentável dos recursos naturais. É preciso, portanto, repensar o sistema dominante e estabelecer um contraponto a esse modelo. Propor ações sustentáveis para a vida na Terra é o papel a ser desempenhado por uma EA crítica em relação ao uso da água, não só nos momentos de escassez hídrica, mas de forma contínua e permanente nos momentos de "normalidade", principalmente.

Considerando as ações colocadas em prática para fazer frente à crise de escassez hídrica no DF no período de 2017 a 2018, com base nos dois documentos analisados nesta pesquisa - o "Plano Integrado de Enfrentamento à Crise Hídrica" (2017a), em suas dimensões educação e comunicação, e a cartilha "Mensageiros da Água - Orientações para práticas pedagógicas" (2017b) - , observou-se que o conjunto de ações de políticas emergenciais para o enfrentamento desse evento extremo foi conjuntural e não estrutural, calcado em um viés comportamentalista, tradicional, conservador e pragmático (LAYRARGUES; LIMA, 2014). Portanto, esta pesquisa mostrou que as propostas para a gestão dos recursos hídricos nesse momento específico de escassez hídrica estiveram pautadas em campanhas e ações sem uma visão crítica, favorecendo temas voltados para o estímulo a uma postura individualista e comportamentalista em relação ao uso da água. 
A partir das análises dos documentos oficiais, produzidos de forma emergencial para as ações consideradas de EA no âmbito do DF, percebeu-se que não existiu uma política pública de EA no contexto dos recursos hídricos para os momentos de escassez. No decorrer da crise, houve uma série de ações emergenciais sem nenhum viés crítico, com base em medidas de abordagem conservadora e tradicional. Quando observamos a situação sob o prisma das macrotendências político-pedagógicas, identificamos sobretudo abordagens na perspectiva da EA conservadora.

Chamou a atenção o uso de certos conceitos e expressões que se repetiam nos documentos analisados. Por exemplo, "consumo consciente", "uso racional e sustentável da água", "eficiência", "mudança de padrões de comportamento", "conscientização", "sensibilização" e "capacitação". Trata-se precisamente de um vocabulário que se aproxima muito das correntes conservacionistas e pragmáticas da EA (LAYRARGUES; LIMA, 2014). Com isso, pode-se afirmar que conceitos ligados a uma EA crítica - como, por exemplo, "mobilização", "participação social", "emancipação", "socioambiental", "cidadania", "transformação social”, "autonomia", "inclusão", "diálogo", "conflito", "democracia", "reflexão", "construção", "justiça ambiental", "cultura", "política" e "emancipação", entre outros - estão ausentes nesses documentos.

Em suma, o que se pôde verificar foram ações planejadas já no decorrer da crise, nas quais não havia uma política ou instrumento pronto para ser implementado naquele momento de emergência. Dessa forma, esta pesquisa recomenda outros estudos que possam contribuir para a edição de uma lei, de uma resolução ou de um decreto que contemple e implemente, de forma participativa, uma política pública de EA com base em uma abordagem crítica, para um real enfrentamento de eventos extremos, como os de escassez

\section{Agradecimentos}

Os autores agradecem à Agência Nacional de Águas (ANA), ao Programa de Mestrado Profissional em Gestão e Regulação de Recursos Hídricos (ProfÁgua-UnB), ao Grupo Pesquisador em Educação Ambiental, Comunicação e Arte (GPEA) da Universidade Federal de Mato Grosso (UFMT) e à Secretaria de Estado de Educação do Distrito Federal (SEEDF), pelo apoio para a realização desta pesquisa.

\section{Referências}

BOMFIM, A.M.; DIAS, B.C. A "Teoria do Fazer" em Educação Ambiental Crítica: uma reflexão construída em contraposição à Educação Ambiental Conservadora. In: VIII Encontro Nacional de Pesquisa da Associação Brasileira de Pesquisa em Educação em Ciências (Enpec). Anais [...]. Universidade Estadual de Campinas, Campinas, SP, 2011. Disponível em: $<$ https://bit.ly/2WgNfol>. Acesso em: 28 nov. 2020. 
BRASIL. Lei $n .09 .433$, de 8 de janeiro de 1997. Institui a Política Nacional de Recursos Hídricos, cria o Sistema Nacional de Gerenciamento de Recursos Hídricos, regulamenta o inciso XIX do art. 21 da Constituição Federal, e altera o art. 1. da Lei n. .0 .001 , de 13 de março de 1990, que modificou a Lei n.. 7.990, de 28 de dezembro de 1989. Diário Oficial [da] República Federativa do Brasil, Brasília, DF, 09 jan. 1997. Disponível em: <https://bit.ly/2K8nbcs>. Acesso em: 28 nov. 2020.

DINIZ, N.S.M.; MARANHÃO, R.R. Educação Ambiental, participação e Gestão das Águas. In: PAULA JÚNIOR, F.; MODAELLI, S. (org.). Política de Águas e Educação Ambiental: processos dialógicos e formativos em planejamento e gestão de recursos hídricos. Brasília: Ministério do Meio Ambiente; Secretaria de Recursos Hídricos e Ambiente Urbano, 2011. p. 75-79.

GAUDIANO, Edgar J.; CARTEA, Pablo Á. Meira. Environmental education under siege: Climate radicality. The Journal of Environmental Education, v.10 Mar., 2020, p. 386-402.

GOVERNO DO DISTRITO FEDERAL (GDF). Mensageiros da Água Orientações para práticas pedagógicas. Brasília: Ibram/Caesb, 2017b. Disponível em: <https://bit.ly/3aiAlym>. Acesso em: 28 nov. 2020.

GOVERNO DO DISTRITO FEDERAL (GDF). Plano Integrado de Enfrentamento à Crise Hídrica. Brasília: Governo de Brasília, 2017a. Disponível em: <https://bit.ly/3h12cEN>. Acesso em: 28 nov. 2020.

GUIMARÃES, M. Educação Ambiental Crítica. In: LAYRARGUES, P.P. (coord.). Ministério do Meio Ambiente. Secretaria Executiva. Diretoria de Educação Ambiental. Identidades da Educação Ambiental Brasileira. Brasília: Ministério do Meio Ambiente, 2004. p. 25-34. Disponível em: $<$ https://bit.ly/2IPESgk>. Acesso em: 28 nov. 2020.

GUIMARÃES, Mauro. Por uma Educação Ambiental Crítica na Sociedade Atual. Revista Margens Interdisciplinar, v. 7, n. 9, Dossiê Educação Ambiental, 2013. Disponível em: <https://bit.ly/37inkCW>. Acesso em: 28 nov. 2020.

GUIMARÃES, M.; RODRIGUES, J.N. Educação Ambiental Crítica na Formação do Educador: uma Pedagogia Transformadora. In: 33. ${ }^{-}$Reunião Anual da Associação Nacional de Pós-Graduação e Pesquisa em Educação (Anped) Educação no Brasil: o balanço de uma década. Anais [...]. Caxambu, MG, 2010. Disponível em: <https://bit.ly/2We96Nj>. Acesso em: 28 nov. 2020.

LAYRARGUES, P.P. Educação Ambiental nas Sociedades Capitalistas. Nuevamerica. La Revista de La Pátria Grande, n. 157, jan.-mar., Rio de Janeiro, 2018.

LAYRARGUES, P.P. Manifesto por uma Educação Ambiental indisciplinada. Ensino, Saúde e Ambiente, Número Especial, p. 44-87, Rio de Janeiro, jun., 2020a. Disponível em: <http://bit.ly/3mnF2ZZ>. Acesso em: 28 nov. 2020. 
LAYRARGUES, P.P. O Cinismo da Reciclagem: o significado ideológico da reciclagem da lata de alumínio e suas implicações para a Educação Ambiental. In: LOUREIRO, C.F.B.; LAYRARGUES, P.P.; CASTRO, R.S. (org). Educação Ambiental. São Paulo: Cortez, 2002.

LAYRARGUES, P.P. Pandemias, colapso climático, antiecologismo: Educação Ambiental entre as emergências de um ecocídio apocalíptico. Revista Brasileira de Educação Ambiental, São Paulo, v. 15, n. 4: 01-30, 2020b.

LAYRARGUES, P.P.; LIMA, G.F.C. As Macrotendências Político-Pedagógicas da Educação Ambiental Brasileira. Ambiente \& Sociedade, v. XVII, n. 1. p. 2340, São Paulo, jan.-mar, 2014.

LIMA, G.F.C. Educação Ambiental crítica: do socioambientalismo às sociedades sustentáveis. Universidade Federal da Paraíba. Educação e Pesquisa, São Paulo, v. 35, n. 1, p. 145-163, jan./abr., 2009.

MARCATTO, C. Educação Ambiental: conceitos e princípios. Belo Horizonte: Fundação Estadual do Meio Ambiente (Feam), 2002. Disponível em: $<$ https://bit.ly/37mHZ9c $>$. Acesso em: 28 nov. 2020.

ORGANIZAÇÃO PARA A COOPERAÇÃO E DESENVOLVIMENTO ECONÔMICO (OCDE). Governança de Recursos Hídricos no Brasil. Paris: OECD Publishing, 2015. Disponível em: <https://bit.ly/387btXL>. Acesso em: 28 nov. 2020.

PAULA JÚNIOR, F.; MODAELLI, S. (orgs.). Política de águas e Educação Ambiental : processos dialógicos e formativos em planejamento e gestão de recursos hídricos. 3. ed., rev. e ampl. Brasília: Ministério do Meio Ambiente; Secretaria de Recursos Hídricos e Ambiente Urbano, 2013. Disponível em: $<$ https://bit.ly/38b9AZZ>. Acesso em: 28 nov. 2020.

PAULA JÚNIOR, F.; ZARDO, S.P. A Água como Direito Humano: contribuições da Educação em Direitos Humanos e da Educação Ambiental para os processos formativos, para a sustentabilidade e a democracia. In: IX Encontro Nacional da Associação Nacional de Pós-Graduação e Pesquisa em Ambiente e Sociedade (Anppas) - Conexões - democracia - sustentabilidade. Anais [...]. Brasília, 2019. Disponível em: <http://www.anppas.org.br/novosite/index.php>. Acesso em: 28 nov. 2020.

ROSSI, M.S. Governança da água na experiência de elaboração do ZEE do Distrito Federal. Brasília em debate, 8.ํ Fórum Mundial da Água, Companhia de Planejamento do Distrito Federal (Codeplan), n. 18, p. 27-35, Brasília, mar. 2018. Disponível em: <https://bit.ly/3oTaH7l>. Acesso em: 28 nov. 2020.

SATO, M. et al. Os condenados da pandemia. Cuiabá: GPEA; UFMT; Ed. Sustentável, 2020.

SECRETARIA DE ESTADO DE COMUNICAÇÃO DO DISTRITO FEDERAL (SECOM). Dicas Economia de Água. Publicidade, Campanhas, 2017. Disponível em: <https://bit.ly/385plB|>. Acesso em: 28 nov. 2020.

SORRENTINO, M. et al. Educação Ambiental como política pública. Educação e Pesquisa, São Paulo, v. 31, n. 2, p. 285-299, maio/ago., 2005. 